\title{
LA PESADILLA DE LA ANTROPOLOGÍA NATURALISTA: LA CONCIENCIA
}

\author{
Salvador Anaya González. Universidad de Sevilla
}

\begin{abstract}
Resumen: La antropología filosófica naturalista hace un tratamiento reduccionista de la conciencia que adultera la forma en la cual el ser humano se ha entendido siempre, pero no solo naufraga en su intento de naturalizar lo humano en cuanto humano, sino que también desnaturaliza lo humano en cuanto Ser. La conciencia no puede someterse a los criterios de verdad de la ciencia actual, pero tiene su confirmación en ella misma, porque como nos enseña la fenomenología no hay experiencia más radical que la conciencia.

Palabras clave: antropología, naturalismo, conciencia, fenomenología, ser.

The nightmare of naturalist anthropology: conscience.

Abstract: Naturalistic philosophical anthropology makes a treatment of reductionist consciousness that adulterates the way in which human beings have always understood each other, but not only shipwrecked in their attempt to naturalize the human in terms of human but also denaturalize the human in terms of Being. Consciousness cannot submit to the truth criteria of current science, but it has its confirmation in itself because, as phenomenology teaches us, there is no experience more radical than consciousness itself.

Keywords: anthropology, naturalism, consciousness, phenomenology, being.

Recibido: 10 de marzo de 2020. Aprobado: 1 de junio de 2020.
\end{abstract}

\section{Introducción}

Este artículo es una crítica a la antropología filosófica naturalista, pero no porque haya fracasado experimentalmente en su intento de reducir todo lo humano a lo natural, sino porque ha convertido la conciencia en una herramienta del cerebro y, los más atrevidos, en un epifenómeno sin ninguna relevancia causal. Una degradación de la conciencia muy problemática porque la idea de sujeto humano no debe de girar en torno a sus accidentes, ni a sus funciones, sino en torno a lo más esencial, y lo más radical del sujeto es la conciencia.

En mi opinión, el estudio del sujeto, y en su defecto de la subjetividad, pasa por el estudio de la conciencia, un estudio que no puede seguir el criterio de verdad de la ciencia, pero no porque lo infrinja, sino porque es la 
propia ciencia la que está verificando que su actual criterio de verdad es insuficiente para explicarla. El criterio de verdad de la conciencia reside en ella misma, de hecho, si algo nos enseña la fenomenología es que la experiencia más real es aquella que se nos da introspectivamente, aquella que remite a la conciencia y por tanto no hay experiencia más radical que la conciencia misma.

Sé que soy un sujeto, pero si me preguntan qué soy, o qué clase de sujeto soy, solo podré responder, dejando todo lo corporal a un lado, enumerando mis propias facultades psíquicas, pero en realidad ni el pensamiento piensa, ni la voluntad quiere, ni el sentimiento siente, sino que lo hace un sujeto, son actos constitutivos, pero al fin y al cabo actos y, por tanto, funciones del sujeto. Aunque dejemos de pensar, de querer o de sentir seguimos teniendo evidencia de ser uno y el mismo sujeto y, por tanto, captamos la diferencia entre el sujeto y sus facultades.

Sin embargo, si quitamos la conciencia, nos quedamos sin pensamiento, sin sentimiento, nos quedamos sin subjetividad y sin sujeto. De modo que, en mi opinión, lo complicado no es demostrar que la conciencia es algo consustancial al sujeto, sino precisamente que se trata meramente de una facultad, porque la experiencia objetiva de ser conscientes es indiscernible de cualquier experiencia que podamos tener del sujeto, de modo que los límites objetivos del conocimiento del sujeto son los límites de la conciencia.

Así pues, este artículo es una crítica a la antropología filosófica naturalista, a una explicación del ser humano que es contradictoria con lo que nos dicta la experiencia fenomenológica más inmediata y espontánea sobre nosotros mismos, una crítica en base al tratamiento naturalista de la conciencia.

\section{Antropología filosófica naturalista}

La antropología filosófica naturalista, en adelante, naturalismo a secas, parte de una metafísica monista y materialista que casa muy bien con los 
La pesadilla de la antropología naturalista: la conciencia

presupuestos metodológicos de las ciencias, de modo que el conocimiento avanza seguro apoyado en la experiencia empírica, y lo primero que nos ofrece la ciencia es que a nivel biológico el ser humano es un animal más, de manera que los esfuerzos se deben centrar en hacer lo mismo con la conciencia.

Pues bien, como de lo que se trata es de demostrar que la conciencia humana tiene su origen en el ámbito natural, y si el naturalismo se limitase a los logros de la ciencia, entonces este artículo empezaría y acabaría con una sola frase, "no hay forma de meterle el diente a la conciencia". Pese al empeño científico y no tan científico de naturalizarlo todo, semejante fenómeno no se deja naturalizar. No entraremos en detalles, quien quiera documentarse puede recurrir al libro La conciencia inexplicada de Juan Arana, donde deja bien claro que no sabemos cómo desde el cerebro emerge la conciencia.

Ni la conciencia humana ni ninguna otra conciencia, no sabemos cómo desde lo físico emerge, surge o aparece lo mental. Pero no tenemos que renunciar a ello, quizá haga falta todavía que el naturalismo pelee algunas batallas más antes de ganar la guerra, o no, porque a decir verdad los naturalistas del pasado lo intuían, los del siglo XIX empezaron a verlo claro, los de finales del XX lo tenían en la punta de la lengua, pero actualmente en lugar de terminar de cuajar el asunto lo que reina es el escepticismo. A pesar de que hemos explorado el universo de lo grande y de lo pequeño, la manera por la cual se las arregla el cerebro para crear la experiencia consciente es una absoluta incógnita.

Pero no se trata de dar carpetazo al asunto, porque si el naturalismo no ha conseguido sus propósitos está en ello y su primera premisa es que la diferencia entre el ser humano y el resto de los animales no es cualitativa sino cuantitativa, solo de grado, y tiene su justificación en la evolución natural. La tarea naturalista debería pasar por probar que la conciencia humana es el corolario evolutivo de otros tipos de conciencia menos desarrolladas. De hecho, nadie duda que los chimpancés o los perros son conscientes, lo que ocurre es que esto le podría servir a los naturalistas para 
defender que la diferencia de la conciencia humana es solo de grado, pero no para demostrar que es algo natural, porque perros y chimpancés podrían revindicar su condición sobre-natural.

El naturalismo tiene que ir más atrás, mucho más. Por eso es muy común entre las filas naturalistas aceptar el biopsiquismo: la razón es que la ciencia, de momento, no puede explicar en términos meramente naturales el hecho probado de que los seres vivos no son sistemas reactivos, sino que captan y procesan coherentemente la información según algún criterio discriminativo o valorativo. O sea, el psiquismo se acepta por motivos epistemológicos, nunca ontológicos, para dar cuenta de lo que de momento se resiste a la explicación natural, pero entonces, aunque se trate de lombrices, moscas o simplemente de células, tampoco se puede asegurar que lo psíquico sea algo natural.

Pero si se trata de la conciencia no se puede llegar hasta el principio de la vida porque evidentemente nadie admite que las bacterias o los girasoles sean seres conscientes, de modo que la pregunta es hasta dónde podemos retroceder sin que el significado de conciencia humana quede irreconocible. Porque todos los seres vivos podrían ser organismos psíquicos, pero cuando se trata de la conciencia hay un salto, una frontera, por muy pequeña y tenue que sea una luz es radicalmente distinta a la oscuridad.

Aunque algunos científicos fijan un criterio estructural que marca la diferencia, en realidad, si afírmanos que un animal es consciente es porque lo deducimos por su comportamiento, porque la conciencia le sirve para algo que puede ser identificado por un observador. Los científicos aseguran que muchos animales poseen los sustratos neurológicos necesarios para la experiencia consciente, pero en realidad no sabemos que tal o cual animal realiza determinadas funciones conscientes porque su cerebro tenga unas características determinadas, sino que porque las realiza es que decimos que tales estructuras cerebrales tienen ese cometido.

Con la conciencia no se puede llegar hasta el fondo de la vida, pero al intentar explicar la conciencia humana desde la base de la pirámide zoológica hay que aceptar necesariamente una analogía bajo un acuerdo de 
La pesadilla de la antropología naturalista: la conciencia

mínimos funcional. De este modo se aceptará que la conciencia es una facultad por la cual el ser vivo procesa la información de forma diferente, por tanto, la conciencia sería en su origen meramente la facultad de darsecuenta-de, o sea, antes que nada, la conciencia sería conciencia sensorial, que a efectos prácticos es lo mismo que captar información estimular, algo que hacen todos los seres vivos.

Para el naturalismo la conciencia es conciencia sensorial en su origen y tiene que darle una explicación funcional, por tanto la explicación evolucionista de la conciencia tiene que justificar su utilidad biológica, tiene también que explicar todo aquello que la conciencia humana hace además de darse-cuenta como un añadido o una emergencia evolutiva y tendría también, si fuese posible, que explicar el salto desde la manera de darse-cuenta de los seres vivos que no son conscientes a los que sí lo son, o sea, explicar el paso de lo inconsciente a lo consciente.

Empecemos por esto último, aunque ya sabemos que es algo que ignoramos y por tanto hay que ser benevolentes con quien se embarca en esa aventura. Antonio Damasio lo explica más o menos así: cada actividad física, cada estímulo externo o interno, deja una huella electroquímica en el cerebro, de modo que la actividad se fija en mapas. Los mapas más estables quedan fijados en una recopilación coherente de patrones neurales y de ahí se produce la imagen, pero ojo, se trata de una imagen inconsciente. Hasta aquí no habría ninguna diferencia con los seres vivos no conscientes.

Ahora bien, en mi opinión, si la imagen, sea consciente o inconsciente, no es más que el correlato de los mapas cerebrales, por lógica, no podría contener más información que la que sirvió para que el cerebro la creara, de modo que el proceso sería inútil, que a fin de cuentas es lo que se está cociendo últimamente entre las filas naturalistas. Por ejemplo, Max Velmans concluyó que la conciencia solo es un subproducto del procesamiento 
de información ${ }^{1}$, que la experiencia consciente siempre sigue al procesamiento y por tanto no puede incidir en él. En esa línea otros muchos afirman que "la experiencia consciente... es epifenoménica con respecto al procesamiento de la información y el funcionamiento cerebral".

La verdad es que resulta un poco chocante que la epistemología evolucionista se haya esforzado tanto en darle a la conciencia una explicación funcional para que ahora se proponga que en realidad no sirve para nada. Pero servir sí que sirve, ya que en la imagen la información se sintetiza y se transforma, pues se lleva a cabo un proceso discriminativo que fija la atención en unos estímulos en detrimento de otros, selecciona los datos según algún criterio valorativo, pero entonces ya no basta la conciencia sensorial, sino que necesariamente hay que admitir, como hace Damasio, la presencia de un proto sí-mismo para quien la imagen tenga sentido.

Como he dicho que hay que ser benevolentes no me extenderé, valga decir que ni Damasio ni nadie sabe cómo de los mapas emerge la experiencia consciente, tampoco cómo surge ese sí-mismo, ni cómo se hace cargo del resto de mapas, pero si no admite un sí-mismo no puede justificar por qué los mapas se convierten en imágenes y sirven para algo. Además, si la conciencia sensorial es el correlato de mapas cerebrales, si no se centralizan en un yo, habría una conciencia distinta para cada mapa cerebral, habría conciencia de lo uno y de lo otro: conciencia visual, auditiva, olfativa, etc., una sería la conciencia que ve y otra la que escucha. Por tanto, ese yo, aunque solo sea proto, es necesario, pero además no podría identificarse con una conciencia vidente o escuchante sino con una conciencia que ve y que escucha, lo que es muy diferente.

En mi opinión esta diferencia es clave, ya que habría que distinguir dos tipos de conciencias: la conciencia sensorial y la conciencia de un yo. Pero, si seguimos la lógica naturalista, igual que no tendría sentido que hubiese

1 Velmans, M.: "Is human information processing conscious?" The Behavioral and Brain Sciences, $n^{\circ}$. 14, pp. 651-726. 1991. Citado en: Ruiz-Vargas, J.M. "¿Qué papel juega la conciencia en la memoria?" Anthropos, nº. 189/190, pp. 184-193. 2000.

2 Ruiz-Vargas, J. M.: "¿Qué papel juega la conciencia en la memoria?" Anthropos, n”. 189/190, pp. 184-193. 2000. 
La pesadilla de la antropología naturalista: la conciencia

conciencia sensorial sin información cerebral objetiva, o sea, sin mapas cerebrales, tampoco, y lo más importante ahora, es que hubiese un yo consciente independiente a la conciencia sensorial. Independiente quizá no, pero Damasio necesita que al menos sea concomitante.

$\mathrm{Al}$ menos que en su origen no sirviera para nada hay que admitir que la conciencia sensorial es indiscernible de un sí-mismo consciente, algo que de una manera u otra niega la psicología evolutiva como la del desarrollo, pues admite que la conciencia sensorial es la primera en aparecer tanto filo como ontogenéticamente y es la condición de posibilidad de la conciencia de sí mismo, de la autoconciencia.

Muy brevemente, para la psicología clásica o el constructivismo genésico de Piaget, el momento ontogenético en que el niño es consciente de sí es muy posterior al momento en que la conciencia sensorial es operativa. Parece demostrado que mucho antes de nacer ya evidencia respuestas estimulares. Aunque con sus diferencias, podemos decir que para el paradigma naturalista antes de que aparezca el yo debe haber conciencia primero de los estímulos propioceptivos e interoceptivos y de los estímulos externos, que la repetición estimular es el primer paso de la sensación de permanencia, que mediada pulsional o volitivamente posibilita la identidad del yo.

Así pues, para la psicología del desarrollo, necesidades y estímulos "construyen" un sujeto físico-psíquico, el sujeto humano. Es aquí donde entra en juego la fenomenología, porque todo lo anterior es un postulado teórico que debería corroborarse en la experiencia, pero la experiencia aquí no está precisamente en el mundo objetivo sino en la propia conciencia. Espontáneamente podemos decir que, si por la conciencia sensorial nos damos cuenta-de, por la autoconciencia nos damos cuenta de que nos damos cuenta-de, pero esta idea esconde un salto categorial ya que este darsecuenta que corresponde a la autoconciencia no tiene que ver con el darsecuenta de cosas, con el darse-cuenta-de.

Esta vivencia reflexiva de sabernos ser el sujeto que percibe es algo tan obvio para nosotros que no podemos imaginar que pueda ser de otra manera, 
pero en realidad se nos puede mostrar muy oscuro, ya que, si hacemos el intento de captarnos en actitud cotidiana, teniendo percepciones, el hecho de tenerlas nos descentra y nuestra conciencia está tan enfocada que no puede "mirarse" a sí misma. Mientras estoy percibiendo las cosas no puedo retrotraerme para justificar que el que percibo soy yo, simplemente ejerzo en la conciencia sensorial. Totalmente enfocada en los sentidos la conciencia no es autorreferente y por tanto la autoconciencia queda oscurecida.

Pero en la introspección lo oscuro se hace claro, dado que podemos experimentar el hecho de que la conciencia esté ahí sin necesidad de percepciones. Ya hemos alumbrado una idea de sí-mismo al que remiten, de modo que cada vez que estamos en actitud natural siempre la idea de símismo va implícita en toda conciencia sensorial, según un saber de sí no conceptual que recubre estando presente todo acto de conciencia intencional, de forma que, aunque el sujeto no se capte a sí mismo en la superficialidad de la conciencia sensorial, a ella emerge inevitablemente de las profundidades la evidencia de ese sí-mismo.

En actitud fenomenológica nos sabemos ser el sujeto que tiene percepciones porque nos sabemos sin ellas y, por tanto, el sí-mismo queda identificado en la introspección a una profundidad silenciada cuando la conciencia opera sensorialmente. Pero, aun silenciado, queda un "conocimiento" tácito que hace posible entender la autoconciencia como la facultad de darse cuenta de que somos nosotros los que vemos, escuchamos u olemos. Por tanto, en el ser humano, toda conciencia sensorial implica autoconciencia, todo acto de aprehensión consciente de un objeto implica necesariamente este saberse ser el sujeto que lo aprehende en cuanto que lo hace. Por tanto, la conciencia sensorial y la autoconciencia son modos de darse una misma subjetividad, un mismo yo.

Desde el punto de vista de la psicología del desarrollo, antes de que emerja el sí-mismo, el concepto de conciencia sensorial no sería más que una generalización por la cual unificamos conciencias diferentes: visual, olfativa, táctil, etc. Por tanto, si no hay un yo, la conciencia sensorial es antes que nada sensorial. Pero, como hemos visto, necesariamente la conciencia 
La pesadilla de la antropología naturalista: la conciencia

sensorial implica ya un yo consciente y por tanto en realidad es lo contrario: la conciencia sensorial es antes conciencia que sensorial. Y lo es porque la conciencia humana no necesita lo sensorial para ser una y la misma conciencia, ya que puede ser conciencia racional o emotiva sin dejar de ser la misma, de manera que la conciencia sensorial es uno de los modos en que la conciencia que pertenece al yo puede actualizarse, pero puede hacerlo de otros modos.

En definitiva, el naturalismo no puede explicar cómo del cerebro emerge la experiencia sensorial consciente, tampoco puede explicar cómo aparece un yo, ni como se hace cargo del proceso sensorial, cómo o quién produce la síntesis, pero lo necesita para que la conciencia sirva para algo, sin embargo, para la psicología primero es la conciencia sensorial y a partir de ella se construye el yo. Pues bien, lo cierto es que la experiencia directa de nuestra propia conciencia lo que nos muestra es precisamente que ese yo no es producto sino la condición de posibilidad de la conciencia sensorial.

Las explicaciones naturalistas contradicen la vivencia directa de nuestra propia conciencia, pero ahí no queda el asunto ya que gran parte de lo más granado de la vanguardia naturalista, al llevar sus presupuestos a sus últimas consecuencias, tiene que afirmar que la conciencia es un epifenómeno, el yo una ilusión o el libre albedrio un trampantojo, que el único protagonista es el cerebro, de modo que no solo pone a la antropología en un gran aprieto obligándonos a poner en cuarentena la forma en que siempre nos hemos entendido en cuanto a humanos, sino también en cuanto a Ser.

\section{El todo de la conciencia}

La comprensión espontánea que tiene el ser humano de sí mismo es la de creerse un yo único, individual, una idea de sí mismo que se está poniendo en dudas por la psicología naturalista, pero es que, si en calidad de humano se siente libre y responsable, en calidad de Ser se sabe un sujeto, un todo ontológico, una substancia, todo aquello que se predica del ser en cuanto ser, y es en esta dimensión donde, en mi opinión, la antropología 
naturalista se desvanece. Porque la antropología naturalista es en última instancia una antropología física, y como en otro sitio he argumentado, a nivel físico, como decían los clásicos, todo es devenir, cambio, trasformación.

Desde el punto de vista físico, biológico, todo ser vivo es una unidad sistémica y funcional en la que cada parte ocupa una posición espaciotemporal en el todo, pero las partes se transforman y se renuevan y lo único que permanece es una disposición orgánica recursiva en continua transformación. En la vida todo es devenir y la permanencia no es más que quietud y, por tanto, biológicamente, sinónimo de muerte.

El cuerpo vivo es un todo hecho de partes heterogéneas, una unidad procesual y funcional, por tanto, no cumple los requisitos del Ser, no es una unidad ontológica. Para llegar a esta idea no hay más que hacer una interpretación lógica de los presupuestos reduccionistas que fundamentan el naturalismo, pero, por otro lado, lo generalizable a todo ser vivo es que desarrolla funciones para mantenerse vivo y reproducirse, por tanto, lo primordial es la función y no el modo en que se realiza. Lo que ocurre es que evolutivamente aparecen órganos que se especializan en una función determinada, que asumen en exclusiva, o casi, lo que antes estaba diversificado.

Pero dado que lo primordial es la función, en ningún caso un órgano podría ser el todo del ser vivo sino evidentemente una parte, por tanto, el cerebro no es el todo de lo humano sino una pieza importante, como lo son también el sistema óseo, el digestivo, el motor, etc. Pero si el cerebro no es más que una parte del todo humano y si se acepta que la conciencia emerge desde el cerebro, evidentemente no podría ser tampoco la conciencia el todo humano, solo sería pues un apéndice "inmaterial" del sistema nervioso.

La experiencia de ver acontece en la conciencia, de modo que si la conciencia emerge del cerebro en ningún caso podríamos decir que ver es algo que haga el todo humano. ¿jpor qué entonces decimos espontáneamente que ver u oler son facultades del todo? La respuesta a esta pregunta es, en 
La pesadilla de la antropología naturalista: la conciencia

mi opinión, porque la conciencia es el único todo, la única unidad ontológica a la que tenemos acceso, porque la conciencia habla desde su propio ser.

Como no tenemos acceso a lo que hay fuera sino a su fenómeno, no podemos acceder a la vida en sí, sino que captamos su fenomenicidad proyectando nuestras propias categorías mentales. Pero las categorías metafísicas de lo mental no son las mismas que las de lo físico. A nivel físico todo es devenir, dispersión, y la unidad es siempre unidad heterogénea, de partes, compuesta y, por tanto, cognoscitivamente la idea de unidad física es un derivado de la unidad de la conciencia, que es el único correlato experiencial de la unidad ontológica.

El yo consciente contiene en su propio ser la categoría de unidad, pero no como una herramienta cognoscitiva a su disposición sino como parte constitutiva de su propio ser. Un yo que no se deja atrapar en una representación porque es donde remite y la condición de posibilidad de toda representación, un yo que trasciende toda experiencia porque es quien la constituye, de modo que la dispersión ontológica del viviente cobra unidad epistemológica en su propio fenómeno, porque el fenómeno lo construye el sujeto. La unidad fenoménica de una estrella o de un árbol implica la unidad de la cosa consigo misma, pero esa unidad no es nouménica sino fenoménica, la unidad no está en la cosa sino en la propia conciencia.

La unidad de la percepción consciente no se debe a la información, que es siempre diversa, heterogénea, compuesta, recibida por los distintos canales sensoriales y procesada por diferentes estructuras cerebrales. La información es tal porque admite un acto discriminativo, de forma que si la información se da unitariamente a la conciencia no es porque la unidad la ponga la información sino la propia conciencia. Desde las estrellas hasta los árboles, pasando por las células, no hay nada permanente, todo es devenir, cambio, transformación, no hay nada de lo que predicar la unidad ontológica, es nuestra propia conciencia la que proyecta su unidad esencial en las cosas.

En términos metafísicos diríamos que el yo consciente convierte lo noúmenico en fenoménico, porque el fenómeno es menos ya que implica un 
acto discriminativo de la información objetiva contenida en los mapas cerebrales, pero también es más porque el yo les añade a las cosas la impronta de su propia unidad. Este es otro de los problemas del naturalismo, explicar por qué el yo añade al fenómeno cosas de su propia cosecha. Porque la conciencia podría limitarse a ser un buen apoyo para el cerebro en su tarea de gestionar los recursos que el ser vivo necesita para vivir y reproducirse, pero la conciencia se le va de las manos al cerebro y crea un mundo de ideas, de valores, de creencias, de anhelos e ilusiones, por tanto, a la explicación funcional de la conciencia podríamos decir sí y no. Sí porque efectivamente sirve para todo lo que dicen los psicólogos evolucionistas, y no porque hace muchas otras, porque cobra una autonomía radical de aquellas instancias de donde presuntamente emerge, toma vida propia y se desmarca de la corporalidad, crea sus propios contenidos, sus propias necesidades.

Tenemos que tener en cuenta que, como nos enseñó Kant, el mundo humano no es el mundo objetivo, sino el mundo fenoménico, pero si además la conciencia no es más que una emergencia del cerebro, que no es el todo sino solo una parte del todo humano, entonces el idealismo está servido, uno sería el mundo objetivo y otro el mundo de la conciencia y por tanto llegaríamos a un dualismo implícito, pero no un dualismo epistemológico sino ontológico, porque el yo se sabe ser y aunque sea imaginario y viva en un mundo de fantasías cree ser real, un yo que se sabe único, individual, todo aquello que se predica del Ser.

El yo consciente, mientras siga siéndolo, podrá proclamar dentro de su universo: iyo soy! Un yo que es donde empieza y donde termina todo conocimiento. Lo que han hecho las conciencias de algunos naturalistas es asombroso, han llegado a la conclusión que en su "yo soy" ni es real el yo ni es real el ser. Pero, valga la redundancia, en realidad la conciencia no ha sido nunca real como lo es el mundo sino mucho más, por dos razones, una epistemológica, porque el hecho más real e incuestionable que tiene el ser humano es el de su propia conciencia, y otra ontológica, porque el ser de la conciencia es de lo único que se puede predicar con propiedad el Ser. De modo que, aunque la conciencia naturalista se sepa a sí misma como un 
La pesadilla de la antropología naturalista: la conciencia

epifenómeno, como una ilusión, como dijo Galileo "y sin embargo se mueve"; aunque la conciencia se crea que no es lo que siempre se había creído, nada le impide seguir gritando a los cuatro vientos: iyo soy!

Es curioso, porque aceptando los presupuestos naturalistas al respecto, en realidad a lo que llegamos es a un dualismo implícito, porque la unidad del ser humano se descompone en dos mundos irreconciliables, el mundo real y objetivo del cuerpo y el mundo psíquico imaginario de la conciencia, donde aparece un yo ilusorio que se cree real. Pero, aunque sea imaginario, es ese el yo que plantea las preguntas y propone las respuestas. Si prescindimos de él nos quedamos sin ciencia, sin filosofía y sin antropología. Ahora bien, si el naturalismo de momento ha fracasado en su tarea de naturalizar la conciencia, entonces, ni siquiera eso que parece tan evidente queda claro, que a nivel biológico el ser humano es un animal como cualquier otro. Intentemos justificarlo.

\section{La unidad del cuerpo humano}

Si el cuerpo vivo es una realidad procesual, si se transforma cada instante, si todo es devenir, sus cambios son accidentales y sustanciales a la vez, no se trata de mantener el equilibrio de un sistema fijo sino un continuo proceso de equilibrio por el cual los estímulos internos y externos, en razón de su relevancia, el cuerpo asimila, de manera que suponen cambios sustanciales, pero no porque haya que entender el cuerpo como algo sustancial, sino porque siendo la suma de los procesos biológicos que lo conforman, su reconfiguración y la aparición de otros nuevos implican la trasformación del todo. Pues bien, igual que ocurre con los estímulos internos y externos, sería lógico admitir que, cuando apareció filogenéticamente la conciencia, no pudo ser algo inocuo para el cuerpo, sino que, igual que el cuerpo asimila, acopla e integra la información relevante, tuvo que hacer lo mismo con la información que recibía de la conciencia.

Cuando apareció la conciencia tuvo necesariamente que incidir causalmente en el cuerpo y, por tanto, aunque sus efectos causales no podrían 
sobrepasar las posibilidades evolutivas, sí que tuvo que incidir en el desarrollo filogenético, de modo que cuando apareció la conciencia el cuerpo ya no solo reaccionaba a los estímulos externos e internos, sino que era también sensible a los estados subjetivos. Ya no se trataba solo de procesar la información física, como el espectro de luz, ahora también podía procesar la imagen; antes podía discriminar la frecuencia de ondas sonoras, ahora el sonido en sí; antes podía captar las sustancias moleculares que provocan el olor, ahora es sensible al olfato.

Pero no porque el cerebro vea o escuche, sino porque cada imagen, cada olor y cada sentimiento produce un efecto fisiológico en el cerebro. La repetición de esos estímulos o su relevancia fijaran proporcionalmente la experiencia en el cuerpo, incidirá y determinará una nueva gama de procesos biológicos. Evidentemente, el buen uso de la información subjetiva sería un valor adaptativo innegable y por tanto iría superando paso a paso la criba selectiva natural.

¿Cuáles serían esos nuevos procesos que se desarrollaron con la aparición filogenética de la subjetividad? La respuesta es bien fácil: los procesos cerebrales conscientes. El sistema nervioso humano es el resultado evolutivo de un proceso por el cual a las estructuras sensoriales o emocionales primitivas, que han sido siempre operativas sin necesidad de conciencia, se han superpuesto otras estructuras relativas a la dimensión consciente, de modo que queda claro que cerebro y conciencia se desarrollaron progresivamente en un intercambio causal recíproco, pero no necesariamente porque el cerebro sea causa suficiente para la conciencia como sostienen los naturalistas, sino porque con la aparición de la conciencia el cuerpo incorporó una nueva gama de procesos que se fueron perpetuando por su valor adaptativo. En ese juego, lo inconsciente y lo consciente se unieron en un todo, en un sistema, de modo que hablar de dos fenómenos distintos no es sino una abstracción.

En mi opinión, el problema de distinguir entre procesos cerebrales conscientes e inconscientes no es solo hacer una abstracción de una realidad única, el cerebro humano, sino sobre todo llamar conscientes a los procesos 
La pesadilla de la antropología naturalista: la conciencia

cerebrales, de modo que el cerebro no es una masa de neuronas a la que se añade la conciencia, sino un cerebro conformado filogenéticamente en su relación con la conciencia y que se desarrolla en una actividad cerebral de la que la conciencia forma parte, de modo que hay una diferencia radical con la corporalidad de los seres vivos no conscientes, pero no hay que entender esta diferencia solo funcionalmente ya que aunque los neurocientíficos aseguren que la conciencia "trabaja en la cabeza" en realidad "vive" en todo el cuerpo.

Recurramos otra vez a la fenomenología. Podemos ensimismarnos tan profundamente en un pensamiento que la conciencia solo "trabaja" en la cabeza, allá donde se concentran las ventanas sensoriales y se agrupan las terminaciones nerviosas, pero podemos enfocar la conciencia en un pie, sentirlo, hacerlo consciente, de modo que la ubicación de la conciencia se reparte entre la cabeza y el pie, pero si se trata de un dolor muy fuerte y nos concentramos en él parece que abandona su ubicación natural en la cabeza y la conciencia se polariza especialmente en el pie.

La vivencia fenomenológica de las sensaciones propioceptivas nos muestra que la conciencia puede "situarse" en cualquier lugar del cuerpo que tenga terminaciones nerviosas, de modo que la conciencia hace de su propio cuerpo una unidad de sensación. La conciencia reclama para sí el cuerpo como un todo y, por tanto, le confiere al cuerpo unidad del ser. Aunque la conciencia no llega al noúmeno de los cuerpos objetivos sino a su fenómeno, cuando se trata de su propio cuerpo capta ambas cosas, perceptivamente como fenómeno y vivencialmente como noúmeno.

Es la diferencia entre el cuerpo objetivo y el cuerpo vivido de la fenomenología, una diferencia que deja claro que la cosa en sí del cuerpo humano no puede reducirse a un agregado de células y funciones al que se superpone tangencialmente la conciencia, sino un cuerpo cuya forma de ser es producto también de la conciencia y, por tanto, toma prestada de ésta su unidad ontológica. Visto así, ni siquiera eso que parece tan obvio, que el cuerpo humano, o en general el cuerpo de los seres vivos conscientes, sea igual de natural que el resto de los seres vivos tampoco estaría nada claro, 
pues solo se podría admitir si se hubiese conseguido demostrar que la conciencia es algo natural, pero no es así.

En realidad, nadie duda de que el desarrollo cerebral y de la conciencia han ido filogenéticamente paralelos. Se quiera o no, la conciencia, directa o indirectamente, ejerce causalmente en el cerebro, pero no solo a nivel filogenético. Desde un punto de vista reduccionista era impensable que el estrés o la ansiedad terminara somatizándose en una úlcera de estómago, pero es más interesante el hecho de que la propia actividad mental transforma estructuralmente el cerebro. Se ha comprobado experimentalmente que el ejercicio de la meditación profunda modifica el espesor cortical de áreas frontolímbicas; la actividad neural mejora el funcionamiento cognitivo y una mayor concentración de materia gris en el hipocampo y en la región orbitofrontal medial, entre otros cambios anatómico-cerebrales ${ }^{3}$.

Está demostrado que los ejercicios físicos tienen sus consecuencias mentales, pero, en la actualidad, ya nadie se atreve a negar que también ocurre a la inversa, pues bien, sin ningún ánimo de exhaustividad, quiero plantear la posibilidad de que la conciencia no es, o no solo es, el producto de la actividad cerebral, de los mapas, sino que podría ser que la conciencia interviene a priori en la configuración cerebral de la experiencia consciente, o sea, que la propia conciencia interviene en construir esos mapas.

\section{La conciencia como causa}

Si seguimos la lógica naturalista habría que decir, por ejemplo, que las terminaciones nerviosas de nuestra mano reciben estímulos externos que viajan hasta el cerebro y producen mapas o patrones neurales desde donde emerge la sensación como una experiencia subjetiva y consciente, un viaje que dura muy poco, pero, aunque poco, tiene duración. Por tanto, si se pudiera reproducir el estímulo directamente en el cerebro, por lógica, la

3 Vid. Valderas J. M.: "Introducción a la neuroteología: Una aproximación a las bases neuronales del fenómeno religioso", Escritos del Vedat, n ${ }^{\circ} .43$, pp. 7-64. 2013. $<$ https://dialnet.unirioja.es/servlet/articulo?codigo=4693515. $>$ [Consultado 4.4.2015]

Naturaleza y Libertad. Número 14, 2020. ISSN: 2254-9668 
La pesadilla de la antropología naturalista: la conciencia

sensación sería más inmediata. Pues bien, Libet es famoso por sus experimentos sobre el libre albedrío, pero quizá sea más interesante un experimento que demostró precisamente lo contrario, o sea, que la estimulación directa de la mano produce un acto consciente inmediato y que si se estimula directamente la corteza cerebral tarda una fracción de segundo.

De este experimento se han hecho eco autores tan distantes ideológicamente como John C. Eccles o Daniel Dennett, uno para apoyar y otro para negar lo que para Libet parecía evidente, que ese experimento representa

un serio desafío para el materialismo: «...una disociación entre la organización temporal de los eventos "mentales" y "físicos" correspondientes plantearía serias dificultades, aunque no dificultades insuperables, a la teoría de la identidad psiconeuronal» (Libet y otros, 1979: 222) ${ }^{4}$

Si Libet tiene razón, la secuencia naturalista se desbarata, no llegarían los estímulos desde la mano al cerebro y a partir de ahí se produciría la conciencia, sino que el estímulo de la mano y la sensación consciente se daría en un mismo acto, y posteriormente se construirían los mapas cerebrales. Por tanto, en mi opinión, esto dejaría claro que el cuerpo humano, en cuanto que es un cuerpo "consciente", no es equiparable al de cualquier ser vivo no consciente. Pero también ofrece indicios para pensar que en la construcción de los mapas cerebrales ya interviene de algún modo la conciencia.

Un caso muy particular, que apunta a que la conciencia interviene causalmente en los procesos cerebrales, son los casos de hidrocefalia. Los niños que no tienen hemisferios cerebrales, sino sacos llenos de líquido cerebroespinal, en teoría deberían de estar en estado vegetativo, sin embargo, responden a eventos ambientales y emocionales y pueden desarrollar sus facultades gracias a la estimulación. En realidad, es un hecho que la influencia psicológica, los cursos de meditación o mindfulness, producen cambios sustanciales en los patrones neurales que ayudan notablemente a la recuperación de derrames cerebrales, lesiones o trastornos causados por las

4 Dennet D. La conciencia explicada. Barcelona. Paidós, 1995, p. 169 
drogas, pero casos como estos ponen en evidencia el determinismo cerebral que con tanto ahínco defienden los neurocientíficos. Un caso especialmente relevante es el de Noah Vall, un niño que sorprendió a quienes estudian el cerebro.

Aún en la matriz se le diagnosticó espina bífida e hidrocefalia, causada por un quiste porencefálico destructivo que solo le dejó el $2 \%$ de su cerebro. Los médicos aconsejaron el aborto porque tenía muchas posibilidades de no sobrevivir y, de hacerlo, todas las de ser un vegetal. A pesar de ello sus padres decidieron seguir adelante. Noah fue sometido a una intervención en la espina bífida y drenaron el fluido del cráneo; a partir de ahí los médicos comenzaron a notar una activación y desarrollo de su comportamiento que lo han hecho un niño normal. Su cerebro se ha regenerado. Cómo lo ha hecho es un misterio ya que, aunque existe la posibilidad de que unas zonas del cerebro sustituyan las funciones de otras zonas dañadas y se restablezcan parcialmente, parece imposible que ocurra cuando falta casi todo el cerebro. Este caso ha hecho que definitivamente algunos autores pongan en dudas los presupuestos actuales de la neurociencia:

aunque el cerebro parece ser un centro crucial que regula y mapea diferentes funciones, puede que la actividad cerebral por sí sola no sea la responsable del surgimiento de la conciencia ${ }^{5}$.

Lo que proponen los autores de este artículo es que fue la conciencia y la voluntad, implícita en los ejercicios de estimulación y aprendizaje que siguió Noah, lo que hizo regenerarse al cerebro; algo revolucionario si se tiene en cuenta que los neurocientíficos dan por hecho que la conciencia, la voluntad y el aprendizaje necesitan la corteza cerebral. Pero que nadie piense en abandonar el naturalismo, lo que en el fondo revindica este artículo es buscar a nivel cuántico lo que no se ha encontrado a nivel físico. 
La pesadilla de la antropología naturalista: la conciencia

Proponemos que además de nuestros estados internos de elección (neurogénesis, neuroplasticidad, diferenciación celular, etc.) también nos relacionemos con estados externos de elección (amor, compasión, empatía, emociones, etc.) que contribuyen a su surgimiento. La incertidumbre cuántica parece apoyar la existencia de una propiedad fundamental basada en la cual funciona el universo; lo que significa que incluso la nada del espacio libre tiene una pequeña posibilidad de contener algo. Los resultados no están determinados por eventos anteriores o aleatorios, sino por la conciencia que da lugar a estos resultados.

La última frase de esta cita sería extraordinariamente extraña dentro de las coordenadas naturalistas si no fuese porque parece probado que la presencia de un observador, de una conciencia, modifica los resultados cuánticos. Es obvio que con esto no queda probado que la conciencia ejerce causalmente sobre esos mapas cerebrales de los cuales dice el naturalismo que emerge, pero nada impide proponerlo. Pero todavía podemos llevar la apuesta un poco más lejos y plantear que no fue el cuerpo el que creo y desarrolló la conciencia, sino que también la conciencia moduló filogenéticamente al cuerpo ejerciendo su impronta sobre él. Es obvio que esto violaría la unidireccional causal genotipo-fenotipo que se defiende en genética y aceptar ideas lamarckianas, pero no es algo que se haya refutado tampoco. Que las mutaciones genéticas azarosas produzcan cambios fenotípicos no garantiza que todos los cambios genéticos sean azarosos ni que todos los cambios fenotípicos se deban a mutaciones genéticas.

En la actualidad, algunos de los postulados fundamentales que daban consistencia al naturalismo están siendo objeto de revisiones, empezado por el propio significado y alcance del concepto de materia y terminando con el férreo determinismo genético. Ya hace mucho que se sabe que el fenotipo está sujeto a determinantes causales epigenéticas, pero hasta ahora no se había comprobado que las facultades adquiridas se trasmiten. Sin embargo, un estudio, participado en gran medida por investigadores españoles, ha puesto de manifiesto en ratas que los cambios morfológicos producidos por el ejercicio físico repercuten en una mejora cognitiva que se trasmiten a las crías. 
Los análisis conductuales, estereológicos y de secuencia del genoma completo revelan que la mejora de la cognición paterna es heredada por la descendencia, junto con un aumento de la neurogénesis adulta, una mayor actividad de la citratosintasa mitocondrial y la modulación del perfil de expresión del gen del hipocampo adulto. Estos resultados demuestran la herencia de la mejora de la cognición inducida por el ejercicio a través de la línea germinal, apuntando a la actividad física paterna como un factor directo que impulsa la fisiología cerebral y el comportamiento cognitivo de la descendencia. ${ }^{6}$

Este estudio parece demostrar que determinadas mejoras cognitivas dependen de la línea germinal pues muestran una herencia patrilineal intergeneracional que sugiere un posible mecanismo de herencia epigenética. Por otro lado, el biólogo español Francisco Martínez Mojica y su equipo hace más de una década que han descubierto que determinadas bacterias desarrollan un sistema de inmunidad adquirido que le permite defenderse de los virus. F.M. Mojica estudiaba los mecanismos moleculares por los cuales los microorganismos que habitan en las salinas de santa Pola eran capaces de adaptarse a cambios en la salinidad. En agosto de 1992, analizando la secuencia del ADN, descubrieron un determinado patrón de repeticiones, había "palabras" que se repetían muchas veces y a una distancia regular, algo que no se había visto nunca, algo extraordinario desde el punto de vista biológico.

Comprobaron que esta característica estaba presente en diferentes microorganismos, algo que los llevó a pensar que debía ser muy común y frecuente y por tanto deberían estar cumpliendo una función importante. En 2003, estudiando la secuencia de repeticiones de Escherichia coli descubrieron una secuencia idéntica a la de un virus, pero lo curioso es que la bacteria que tiene esa secuencia no se infecta por ese virus, se trata del descubrimiento de un sistema inmunológico adquirido en las procariotas, algo realmente novedoso.

6 Id. 
La pesadilla de la antropología naturalista: la conciencia

Este sistema fue bautizado como CRISPR (repeticiones palindrómicas cortas agrupadas y regularmente espaciadas, por sus siglas en inglés) que sin duda es uno de los mayores avances de la biología reciente. Los virus introducen parte de sus genes en el ADN de las bacterias, pero gracias a las CRISPR, las bacterias los localizan y los cortan con unas proteínas que funcionan como "tijeras" llamadas Cas9, que eliminan los genes dañinos.

Los trabajos del biólogo español y su equipo han puesto los cimientos de una nueva etapa del desarrollo de la ingeniería genética, pero también han demostrado que las mutaciones genéticas teleológicas son un hecho. En mi opinión, cada vez hay más datos para admitir que cuerpo y conciencia interactúan recíprocamente, son estímulos y agentes causales bidireccionales y, sobre todo, para ser conscientes, nunca mejor dicho, de que la relación de la conciencia y el cuerpo necesita una alternativa distinta a la que ahora maneja el naturalismo.

Salvador Anaya González sanayag@gmail.com

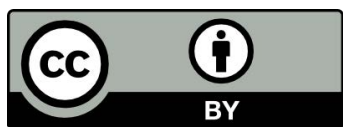

